Décadrages Décadrages

cınéma, à travers champs Cinéma, à travers champs

$7 \mid 2006$

Stephen Dwoskin

\title{
Fragile (2005) de Laurent Nègre : belles querelles
}

\section{Marthe Porret}

\section{(2) OpenEdition \\ Journals}

Édition électronique

URL : http://journals.openedition.org/decadrages/475

DOI : $10.4000 /$ decadrages. 475

ISSN : 2297-5977

\section{Éditeur}

Association Décadrages

\section{Édition imprimée}

Date de publication : 10 avril 2006

Pagination : 119-120

ISBN : 978-29700582-3-6

ISSN : 2235-7823

Référence électronique

Marthe Porret, «Fragile (2005) de Laurent Nègre : belles querelles », Décadrages [En ligne], 7 | 2006, mis en ligne le 30 janvier 2014, consulté le 20 avril 2019. URL : http://journals.openedition.org/ decadrages/475; DOI : 10.4000/decadrages.475

Ce document a été généré automatiquement le 20 avril 2019.

ß Décadrages 


\title{
Fragile (2005) de Laurent Nègre : belles querelles
}

\author{
Marthe Porret
}

1 Nominé pour le Prix du cinéma suisse 2006 de Soleure, Fragile méritait tout autant que Mein Name ist Eugen le titre de Meilleur film de fiction. Eugen, énorme succès populaire en Suisse alémanique ${ }^{1}$, a eu les faveurs du jury. En revanche le film de Nègre a valu à Marthe Keller - royale ! - le Prix du meilleur rôle secondaire.

2 Premier long métrage de Laurent Nègre, né en 1973 à Genève², Fragile impressionne par son aboutissement tant formel que narratif, et par sa direction d'acteurs.

3 L'histoire d'abord, dont l'unité de lieu est Genève, et l'unité d'action les trente-six heures environ qui relatent le suicide d'une mère frappée d'Alzheimer et la longue nuit précédant son enterrement; nuit durant laquelle ses deux enfants, Sam et Catherine, en conflit, vont se confronter et peut-être se retrouver. Le montage achronologique des séquences, astucieux et efficace, participe au ton un peu fantastique et nostalgique de l'histoire.

4 Les dialogues ensuite : très bien écrits, parcimonieux et authentiques, ils donnent lieu à des échanges extrêmement vifs, impertinents et cruels entre Sam et Catherine qui se déchirent. Leur qualité est encore rehaussée par le jeu sobre des acteurs.

5 Nègre, par ailleurs, fait preuve d'un sens original de l'image et du son. S'il filme et utilise le jet d'eau comme un ressort narratif, il réussit à en faire un objet totalement insolite : les images du générique par exemple nous montrent le dispositif qui s'ouvre automatiquement sur la pompe, à la base du jet, de telle sorte qu'il nous faut beaucoup de temps avant de reconnaître la célèbre attraction de Genève. Pour traduire le désarroi dans lequel la maladie plonge Emma, personnage interprété par Marthe Keller, le réalisateur recourt au sein de quelques scènes à des coupures sonores déstabilisantes. Toute la séquence du suicide, très réussie, fonctionne sur l'inattendu - l'attitude calme d'Emma ainsi que ses propos ne nous préparent pas à son geste - et la tension progressive de la musique originale. Enfin, seul le ralenti à peine perceptible de certains travellings et panoramiques traduit visuellement le pathos de l'histoire. Bref, tout concourt à la cohérence de ce très beau film. 
Fragile (2005) Réal. et scénario : Laurent Nègre. Image : Béatrice Mizrahi. Montage : Julien Sulser. Son : Jürg Lempen. Musique : Ladislav Agabekov, Andrès Garcia, Jérôme Pellegrini. Décors : Anne Carmen Vuilleumier. Interprètes : Marthe Keller, Felipe Castro, Stéfanie Günther. Production : Bord Cadre Films Sàrl, Dan Wechsler (Genève). Sortie en Suisse romande le 8 février 2006.

\section{NOTES}

1. Le film de Michael Steiner, qui a déjà dépassé les 530000 entrées, sort en Suisse romande le 22 mars 2006.

2. Après avoir étudié au Centre d'Etudes Cinématographiques de Catalogne à Barcelone, Laurent Nègre sort diplômé de l'Ecole Supérieure des Beaux-Arts de Genève (section cinéma) en 2002. 